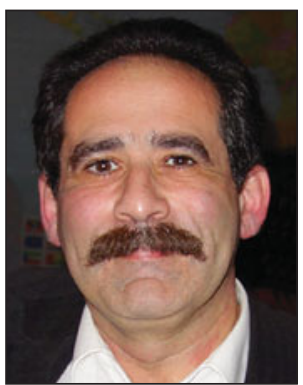

Leon Mishnaevsky Jr.

Guest Editor for this issue of MRS Bulletin

Department of Wind Energy, Technical

University of Denmark, Denmark;

tel. +45 467757 29; and email lemi@dtu.dk. Mishnaevsky is a senior scientist at the Technical University of Denmark. He received his PhD degree from the Russian Academy of Sciences and a Dr. habil. degree from Technische Universität Darmstadt (TU Darmstadt), Germany. $\mathrm{He}$ is the author of more than 120 research papers. Prior to joining TU Darmstadt, he was a Heisenberg Fellow at the University of Stuttgart, and was a visiting professor/scholar at Massachusetts Institute of Technology and Rutgers, The State University of New Jersey; The University of Tokyo, Japan; and École Nationale Supérieure d'Arts et Métiers, France. Mishnaevsky has led several international projects (EU, Danish-Chinese, Danish-Japanese) and is a chairman of many international conferences in composites, nanomaterials, modeling, and energy.

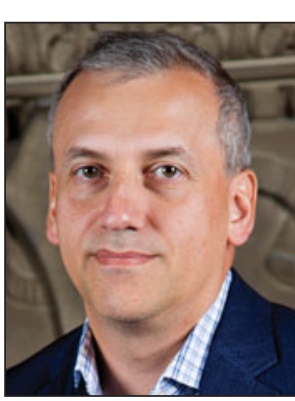

\section{Michael Tsapatsis}

Guest Editor for this issue of MRS Bulletin

Department of Chemical Engineering and Materials Science, University of Minnesota, USA; email tsapatsis@umn.edu.

Tsapatsis is a professor and the Amundson Chair in the Department of Chemical Engineering and Materials Science at the University of Minnesota. He has co-authored approximately 220 publications. Recent accomplishments of his group include the development of hierarchical catalysts and molecular sieve films for membrane applications. His teaching interests include chemical engineering and materials design, with an emphasis on energy efficiency and process intensification. Tsapatsis is a member of the National Academy of Engineering.

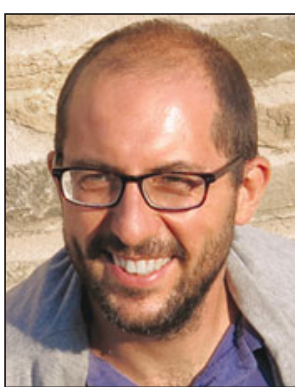

\section{Federico Bosia}

Department of Physics and Nanostructured Interfaces and Surfaces Interdepartmental Centre, University of Turin, Italy; tel.

+390116707889; and email fbosia@unito.it. Bosia has been at the University of Turin in the Solid State Physics Group since 2007. He received his BS degree in physics in 1996 and his $\mathrm{PhD}$ degree in mechanical engineering in 2002 at École Polytechnique Fédérale de Lausanne, Switzerland. He has also worked at the Leibniz Institute for Solid State and Materials Research (IFW Dresden), Germany, and at Politecnico di Torino, Italy. Bosia has published approximately 60 papers on topics related to the mechanics of composite and bioinspired materials, nonlinear elasticity, and acoustics.

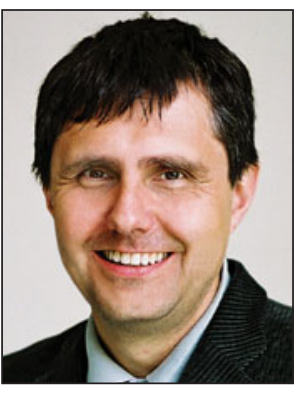

Peter Fratzl

Department of Biomaterials, Campus Golm, Max Planck Institute of Colloids and Interfaces, Germany; tel. +49-331-567-9400; and email fratzl@mpikg.mpg.de.

Fratzl is director at the Max Planck Institute of Colloids and Interfaces in the Department of Biomaterials. He received his engineering degree from École Polytechnique in France and his $\mathrm{PhD}$ degree from the University of Vienna, Austria. His research interests include structure and properties of biological and bioinspired materials. He co-authored over 500 publications and is a recipient of the Leibniz Award. Fratzl is also a member in several Academies of Science in Germany and Austria, and has been an MRS Fellow since 2012.

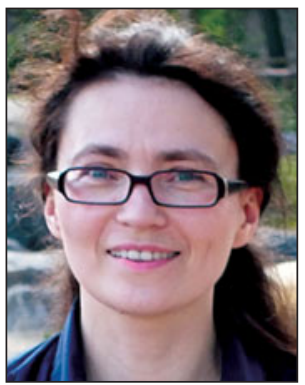

Larissa Gorbatikh

Department of Materials Engineering,

KU Leuven, Belgium; tel. +32-16-32 1235; and email larissa.gorbatikh@mtm.kuleuven.be. Gorbatikh is a research expert in the Composite Materials Group in the Department of Materials Engineering at KU Leuven, where she coordinates research activities in the field of nanoengineered and hybrid polymer composites. She received her master's degree in mechanics from St. Petersburg State University, Russia, in 1997, and her PhD degree in mechanical engineering from Tufts University in 2001. She has co-authored over 120 publications and participated in many European and national projects in the United States, Belgium, and Russia. Gorbatikh currently serves on the council of the European Society for Composite Materials.

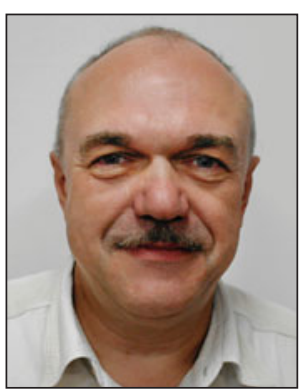

\section{Evgeny Levashov}

Department of Powder Metallurgy and Functional Coatings, Scientific-Educational Center of Self-Propagating High-Temperature Synthesis Center, National University of Science and Technology "MISIS," Russian Federation; tel. +7 4956384500 and email levashov@shs.misis.ru.

Levashov is the head of the Department of Powder Metallurgy and Functional Coatings, director of the Self-Propagating High-Temperature Synthesis Center at the National University of Science and Technology, MISIS, and is also a professor. He received an Honorary Doctorate of Engineering from the Colorado School of Mines in 2007. He is the author of four textbooks, 96 patents, and more than 580 articles. He serves as an editor-in-chief of the Russian Journal of Non-Ferrous Metals. Levashov's research is focused on materials science of functional materials and coatings.

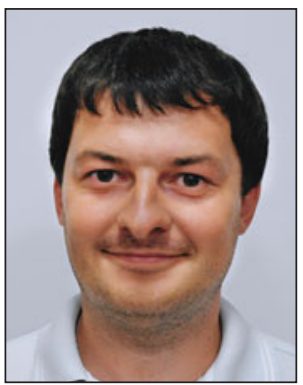

Pavel Loginov

National University of Science and Technology, Moscow Institute of Steel and Alloys "MISIS," Russian Federation; tel. +74952369936; and email pavel.loginov.misis@list.ru.

Loginov is a junior research scientist at the National University of Science and Technology, MISIS. He received his MS degree in 2011 and his PhD degree in 2014, both from the National University of Science and Technology, MISIS. He is the author of 10 research papers. Loginov's scientific interests include powder metallurgy, diamond tools, metal-matrix composites, mechanical alloying, and cutting diamond tools

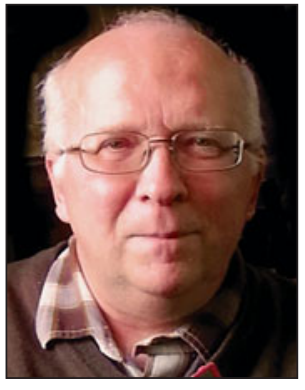

Stepan V. Lomov

Department of Materials Engineering

KU Leuven, Belgium; tel. +32-16-321210; and email Stepan.Lomov@mtm.kuleuven.be. Lomov is a coordinator of the Composite Materials Group in the Department of Materials Engineering at KU Leuven and holds the Toray Chair. His research interests span experimental and theoretical studies of composites and textiles. He has co-authored more than 500 papers, edited two books, and is an editorial board member of Composite Science and Technology, Textile Research Journal, Mechanics \& Industry, and scientific committees of various conferences. Lomov's WiseTex software is licensed to more than 50 industrial and academia users worldwide. 


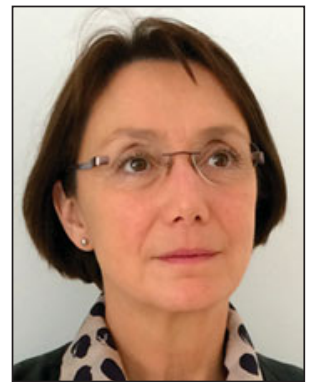

\section{Svetlana Mintova}

Laboratoire Catalyse et Spectrochimie-

ENSICAEN, Université de Caen, CNRS,

France; tel. +33231452737; and

email svetlana.mintova@ensicaen.fr.

Mintova is a research director at the Laboratoire Catalyse et Spectrochimie-ENSICAEN Université de Caen, CNRS. She received her PhD degree in physical chemistry from the Technological University of Sofia, Bulgaria, in 1993. She worked as a docent at the University of Munich, Germany, as a visiting scholar at Purdue University, and as a postdoc at the Luleå University of Technology, Sweden. Mintova's research interests include synthesis of nano-sized porous materials (zeolites) and preparation of films and assemblies related to new applications and processes.

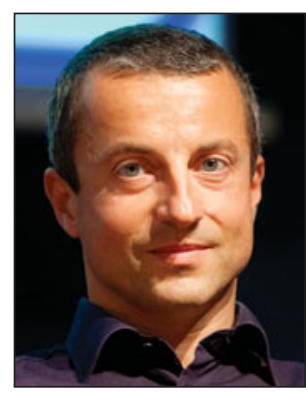

Nicola M. Pugno

Laboratory of Bio-Inspired \& Graphene

Nanomechanics, Department of Civil,

Environmental and Mechanical Engineering,

University of Trento, and Center for Materials

and Microsystems, Fondazione Bruno

Kessler, Italy; and School of Engineering

and Materials Science, Queen Mary

University of London, UK; tel. +39 0461

282525; and email nicola.pugno@unitn.it.

Pugno is a full professor of solid and structural mechanics at the University of Trento, and founder and head of the Laboratory of BioInspired \& Graphene Nanomechanics. He leads the Graphene Nanocomposites grant within the EU Graphene Flagship at the Fondazione Bruno Kessler, Italy, and is a full professor of materials science at the Queen Mary University of London. He received master's degrees in mechanical engineering and theoretical physics, and two PhD degrees in fracture mechanics and biology. Pugno has published approximately 300 journal papers, and has received four grants from the European Research Council.

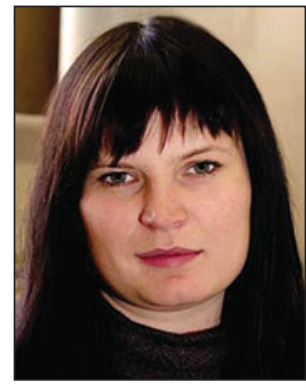

Daria Sidorenko

National University of Science and Technology, Moscow Institute of Steel and Alloys "MISIS", Russian Federation; tel. +74956384442; and email dsidorenko@inbox.ru.

Sidorenko is a research scientist at the National University of Science and Technology, MISIS. She received her MS degree in 2009 and her PhD degree in 2012, both from the National University of Science and Technology, MISIS. She is the author of 15 research papers. Sidorenko's scientific interests include metal-matrix comallurgy, and cutting diamond tools posites, nanomaterials, diamond, powder met-

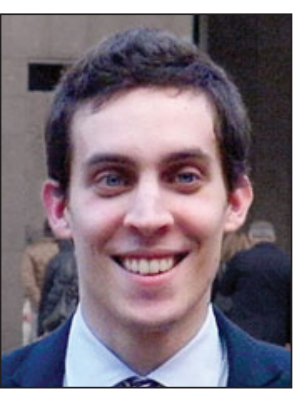

\section{Stefano Signetti}

Laboratory of Bio-Inspired \& Graphene

Nanomechanics, Department of Civil,

Environmental and Mechanical Engineering,

University of Trento, Italy; tel. +390461

282597; and email stefano.signetti@unitn.it.

Signetti is currently a doctoral candidate in solid and structural mechanics at the University of Trento. He received his MS degree in civil engineering from the Politecnico di Torino, Italy, in 2013. His research interests include the mechanics of biological and bioinspired structures involving fracture and fragmentation under high-energy impacts, anticatastrophe civil structures, graphene-based nanocomposites, and tribology of graphene and of bioinspired nanosurfaces.

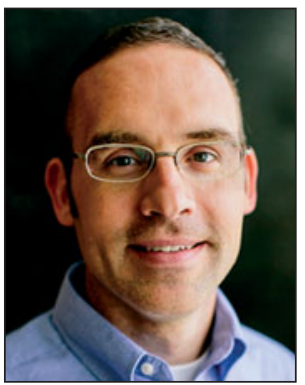

Mark A. Snyder

Department of Chemical and Biomolecular Engineering, Lehigh University, USA; tel. 610758-6834; and email snyder@lehigh.edu. Snyder is an associate professor of chemical and biomolecular engineering at Lehigh University. He received his BS degree from Lehigh University in 2000 and his PhD degree in 2006 from the University of Delaware, both in chemical engineering. Before joining the faculty at Lehigh in 2008, he was a postdoctoral associate in the Department of Chemical Engineering and Materials Science at the University of Minnesota. His research interests include engineering of inorganic nanoparticles, nanoparticle assembly, and template-mediated synthesis of porous inorganic materials for applications spanning catalysis, separations, and electrodes. Snyder is the recipient of an NSF CAREER Award in 2014.

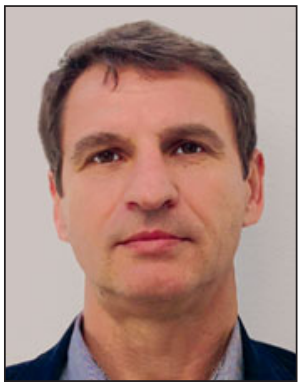

\section{Valentin Valtchev}

Laboratoire Catalyse et SpectrochimieENSICAEN, Université de Caen, CNRS,

France; tel. +33679201146; and

email valentin.valtchev@ensicaen.fr.

Valtchev is a research director at the Laboratoire Catalyse et Spectrochimie-ENSICAEN Université de Caen, CNRS. He studied geochemistry at the University of Sofia, Bulgaria, and received his PhD degree from the Bulgarian Academy of Sciences. He worked as a postdoctoral research fellow from 1992 to 1993 and 1995 to 1996. In 1996, he was promoted to senior researcher at the Bulgarian Academy of Sciences. Valtchev's research interests include synthesis and modification of zeolites and other porous solids that can be used for catalysis, separation, and molecular recognition.

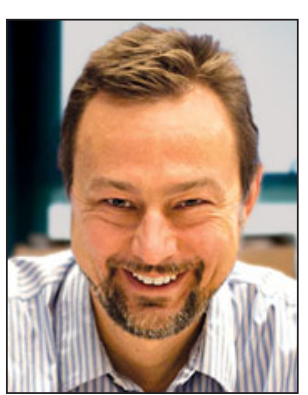

\section{Brian L. Wardle}

Department of Aeronautics and Astronautics, Massachusetts Institute of Technology, USA; tel.617-252-1539; and email wardle@mit.edu. Wardle studies materials and structures in Massachusetts Institute of Technology's (MIT) Department of Aeronautics and Astronautics, with a focus on bulk nanostructured materials and devices. He is the founder and director of the Necstlab Research Group and MIT's NECST aerospace industry consortium. He received his BS degree in aerospace engineering from The Pennsylvania State University in 1992, and his SM and PhD degrees at MIT in the Department of Aeronautics and Astronautics in 1995 and 1998, respectively. He has authored over 90 journal articles and holds five patents with more than 10 other applications pending in the area of nanoengineered materials. Wardle is an Associate Fellow of the American Institute of Aeronautics and Astronautics.

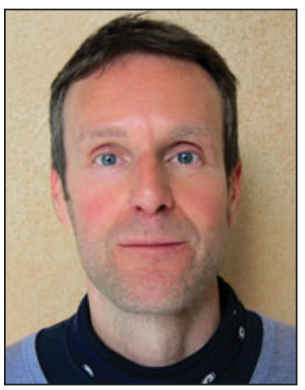

Richard Weinkamer

Department of Biomaterials, Campus Golm, Max Planck Institute of Colloids and Interfaces, Germany; tel. +49 (0) 331567 9410; and email Richard.Weinkamer@mpikg.mpg.de. Weinkamer is a group leader in the Department of Biomaterials at the Max Planck Institute of Colloids and Interfaces. He earned his PhD degree in physics and his MS degree in mathematics from the University of Vienna, Austria, and, in 2012, habilitated in theoretical physics at Humboldt University of Berlin, Germany. Weinkamer's research interests include the adaptive and healing properties of biological materials, particularly bone. 